\title{
Resposta imune a Candida albicans
}

\section{Immune response to Candida albicans}

\author{
Ivete Conchon Costa ${ }^{1}$; Ionice Felipe ${ }^{2}$; Luis Carlos Jabur Gaziri ${ }^{3}$
}

\begin{abstract}
Resumo
Candida albicans causa infecções na pele, cavidade oral e esôfago, trato gastrointestinal, vagina e sistema vascular de humanos. As infecções ocorrem em hospedeiros imunocomprometidos ou pacientes debilitados. Acima de $90 \%$ dos pacientes HIV+ sofrem de candidíase de mucosas ao menos uma vez no decorrer da doença. A severidade e cronicidade da candidíase oral em pacientes com AIDS são atribuídas, principalmente, à imunodeficiência induzida pelo HIV nos indivíduos afetados, a saber, perda de funções de célula T auxiliar e redução do número de linfócitos T CD4. Na colonização de mucosas e infecções sistêmicas de camundongos por este fungo, células Th1 medeiam a proteção dependente de fagócitos, cujas citocinas mais importantes são IL-2, IFN- $\gamma$ e IL-12, TNF- $\alpha$. Ao contrario, produção de citocinas inibidoras tais como, IL-4 e IL-10 por células Th2 estão associadas à desativação de fagócitos e à progressão da doença. Possivelmente, o crescimento de formas filamentosas está melhor adaptado para evadir das células do sistema imune, enquanto a forma de levedura pode ser o modo de proliferação em tecidos infectados. Pela produção discriminativa de IL-12 em resposta a levedura e de IL-4 a hifa, as células dendríticas adquirem a capacidade para induzir a diferenciação de células TCD4 para o fenótipo Th1 ou Th2.
\end{abstract}

Palavras-chave: Candida albicans.Resposta immune.Infecçõs sistêmicas.

\begin{abstract}
Candida albicans causes infections of the skin, oral cavity and esophagus, gastrointestinal tract, vagina and vascular system. Most infections occur in immunocompromised hosts or debilitated patients. More than $90 \%$ of HIV positive patients suffer from mucosal candidiasis at least once in the course of this disease. The overall severity and chronicity of oral candidiasis in patients with AIDS are mainly attributed to the HIV-induced immune deficiency in the affected individuals, namely, the loss of T-helper cells and reduction in the number of $\mathrm{CD} 4+\mathrm{T}$ lymphocytes. In mucosal colonization and systemic infections of mice by this fungus, Th1 cells mediate phagocyte-dependent protection, whose most important cytokines are IL-2, IFN- $\gamma$, TNF- $\alpha$ and IL-12. In contrast, production of inhibitory cytokines such as IL- 4 and IL10 by Th 2 cells are associated with disactivation of phagocytes and disease progression. Possibly, the growth of filamentous forms is better adapted to evade the cells of the immune system, whereas the yeast form may be the mode of proliferation in infected tissues. By the discriminative production of IL12 or IL-4 in response to the yeast or filamentous forms respectively, dendritic cells acquire the capacity of inducing the differentiation of CD4+ cells towards the Th1 or Th2 phenotypes.
\end{abstract}

Keywords: Candida albicans. Immune response. Systemic infection.

Docente do Departamento de Ciências Patológicas. Centro de Ciências Biológicas/UEL. E-mail: conchon@uel.br. Docente do Departamento de Ciências Patológicas. Centro de Ciências Biológicas/UEL.

Docente do Departamento de Ciências Fisiológicas. Centro de Ciências Biológicas/UEL.

Semina: Ciências Biológicas e da Saúde, Londrina, v. 29, n. 1, p. 27-40, jan./jun. 2008 


\section{Introdução}

O conhecimento dos principais mecanismos de defesa contra $C$. albicans permite a melhor compreensão da patogênese da doença e das estratégias que o hospedeiro dispõe para controlála. Nesse sentido, esta revisão pretende apresentar resultados de pesquisas acerca dos mecanismos envolvidos na resposta imune à C. albicans. Esses resultados foram obtidos principalmente por meio de modelos experimentais murinos.

A imunidade à $C$. albicans está presente em indivíduos adultos imunocompetentes, resultado do comensalismo do fungo nas mucosas gastrintestinais do hospedeiro (ROMANI; PUCETTI; BISTONI, 1996). Como comensal, esse fungo, assintomaticamente, coloniza a superfície epitelial, aparentemente, na forma de blastoconídio. Como resultado desta exposição, muitos indivíduos saudáveis desenvolvem imunidade específica à $C$. albicans, detectável por testes cutâneos e a resposta de linfócitos do sangue periférico contra seus antígenos, assim como pela presença de anticorpos específicos no soro e secreção mucosa (ODDS, 1988).

Assim, a permanência do fungo como comensal deve-se a vários fatores, como: a pele intacta, que é protegida por células queratinizadas; a superfície mucosa; a presença de mucinas e de IgA e de numerosas bactérias que fazem proteção, alojandose ao redor do fungo, impedindo sua adesão, além de compartilharem nutrientes com outros organismos comensais (SENET, 1997). Modificações nestas barreiras naturais, como aquelas causadas por antibioticoterapia, corticoterapia, quimioterapia, cirurgias, cateterismos, sondas e cateteres, podem disparar a invasão do fungo e o processo patogênico.

Imunidade inata e adaptativa (celular e humoral) estão envolvidas na proteção contra a infecção por $C$. albicans. Embora cada uma possa contribuir de maneira diversa nos diferentes sítios de infecção, a imunidade inata, por meio de macrófagos e neutrófilos, domina a proteção contra candidemia, enquanto a imunidade celular ativada, predominantemente, por citocinas das células $\mathrm{T}$ CD4+, protege as mucosas da infecção. Em relação à imunidade humoral, existem controvérsias, entre estudos clínicos e modelos em animais, e há dados discordantes acerca do papel efetivo dos anticorpos contra infecções por C. albicans (FIDEL JÚNIOR, 2002).

\section{Células efetoras}

A contenção da invasão do patógeno no hospedeiro exige uma resposta rápida, geralmente promovida pelo sistema imune inato, o qual se desenvolve prontamente e precede à expansão clonal de linfócitos antígenos específicos. O sistema imune inato consiste de células NK, complemento, proteínas plasmáticas e células fagocíticas (ISMAIL et al., 2002), e serve para dois propósitos principais,: atuar como um efeito direto antifúngico pela destruição do patógeno e como uma função instrutiva nas células do sistema imune adaptativo, por meio da produção de citocinas e quimiocinas pró-inflamatórias, da indução de atividades coestimulatórias e da apresentação de antígeno (ROMANI, 2004).

Pacientes com deficiência na imunidade inata, como doença granulomatosa crônica ou neutropenia, são extremamente sensíveis a uma variedade de infecções, entre elas, as fúngicas (LORENZ; FINK, 2002).

Macrófagos e neutrófilos são considerados as principais células envolvidas na defesa do hospedeiro contra infecções por Candida; células dendríticas também têm papel central na defesa contra Candida albicans (D'OSTIANI et al., 2000)

$\mathrm{O}$ reconhecimento do fungo invasivo pelo sistema imune inato é o primeiro passo para a ativação de uma resposta imunológica rápida, o que assegura a sobrevivência após a infecção. Os receptores de fagócitos ao reconhecerem padrões 
moleculares do patógeno, iniciam a resposta imune (GIL; GOZALBO, 2006). Entre estes, citam-se os receptores de manose; receptores semelhantes a Toll (TLRs); receptores de varredura e receptor dectina-1 (UNDERHILL; OZINSKY, 2002). Os fagócitos expressam também receptores para complemento (CR) e anticorpos ( $\mathrm{FcR}$ ), e vários pesquisadores têm demonstrado que a fagocitose de $C$. albicans por fagócitos mononucleares é aumentada quando as leveduras estão opsonizadas com soro normal (VASQUEZ-TORRES; BALISH, 1997; GAZIRI et al., 1999; SANTOS et al., 2002).

Os receptores demanose presentes nasuperfície de macrófagos reconhecem superfície rica em manana, sendo especialmente importantes na fagocitose de C. albicans. A expressão aumentada de receptores de manose, devido ao fator estimulante de colônias de macrófagos (M-CSF) (KARBASSI et al., 1987); do interferon- $\gamma$ (IFN- $\gamma$ ) (MARÓDI; JOHNSTON JÚNIOR, 1993), e da Concanavalina-A (LOYOLA et al., 2002), tem melhorado a capacidade fagocítica de macrófagos. Yamamoto, Klein e Friedman (1997) demonstraram que a fagocitose de levedura, por meio do receptor de manose, resulta em produção de citocinas pró-inflamatórias, degradação do fungo e estímulo de moléculas co-estimulatórias, moléculas de MHC classe II e ativação de resposta celular protetora Th1.

Estudosrecentestêm demonstradooenvolvimento crucial dos TLRs no reconhecimento de C. albicans, e TLR-2 e TLR-4 são os principais TLRs envolvidos no reconhecimento deste fungo (NETEA et al., 2002; NETEA et al., 2004; VILLAMÓN et al., 2004; GIL; GOZALBO, 2006).

Villamón et al. (2004) demonstraram que camundongos knockout TLR2 ${ }^{-/-}$sobreviviam menos à infecção por $C$. albicans do que camundongos normais, apresentando baixa produção de TNF- $\alpha$ e de quimiocina MIP-2; camundongos knockout em TLR4 $4^{-/}$também se mostraram mais suscetíveis à infecção por C. albicans. Nestes, contudo, a suscetibilidade estava relacionada à baixa expressão de quimiocinas e à falha no recrutamento de neutrófilos.

A ligação de distintos receptores para a levedura e para a hifa define a natureza da resposta efetora, a produção de citocinas pró-inflamatórias e a coestimulação (ROMANI; BISTONI; PUCCETTI, 2002; NETEA et al., 2006). As hifas ou as leveduras opsonizadas, quando fagocitadas com envolvimento do receptor $\mathrm{CR} 3$, em associação com receptor $\mathrm{Fc} \gamma$, resultam no aumento de moléculas co-estimulatórias e MHC II, na produção de interleucina-4 (IL-4) e/ou interleucina-10 (IL-10) e na ativação de células Th2 (ADEREM; UNDERHILL, 1999).

Van de Graaf et al. (2005) demonstraram que blastoconídios e hifas de C. albicans diferem no estímulo da resposta no hospedeiro, pois os blastoconídios estimulam ambos receptores TLR-2 e 4, e o último é responsável pela grande produção de IFN- $\gamma$ por monócitos e de fator de necrose tumoral- $\alpha$ (TNF- $\alpha$ ) por macrófagos peritoneais. Hifas, por sua vez, não foram reconhecidas por TLR-4 e induziram grande produção de IL-10, por meio do TLR-2, mas não à produção de IFN- $\gamma$.

Brown e Gordon (2001) identificaram em macrófagos o receptor dectina-1 para $\beta$-glucana. Recentemente, foi demonstrado que em macrófagos incubados com blastoconídio de C. albicans, ocorre a fagocitose dos blastoconídios; a secreção de TNF- $\alpha$, IFN- $\gamma$ e o aumento na produção de superóxido e da capacidade fungicida, com envolvimento de dectin-1, TLR2 e 4. No entanto, na fagocitose de hifas, o receptor dectina-1 não está envolvido, e disso resulta uma resposta antiinflamatória, com a produção de citocinas como IL-10, reduzida produção de superóxido e capacidade fagocítica diminuída (GANTNER; SIMMONS; UNDERHILL, 2005).

Os macrófagos são, geralmente, as primeiras células a interagir com corpos estranhos, por estarem 
presentes nas portas de entrada do organismo. Dependendo do receptor utilizado e do estágio de diferenciação, essas células podem produzir vários produtos secretórios, incluindo citocinas e quimiocinas que mobilizam outras células para o tecido (GORDON, 1998).

Farah et al. (2001) demonstraram, em modelo experimental de candidíase oral, que a inativação de macrófagos por carragenina causava aumento na severidade da infecção nos primeiros oito dias. Do mesmo modo, a eliminação de macrófagos esplênicos murinos, por meio da administração intravenosa da droga difosfato de diclorometileno, aumentou a suscetibilidade a infecções disseminadas por C. albicans e reduziu o tempo de sobrevida desses animais (QIAN et al., 1994).

Neutrófilos constituem um dos principais mecanismos de defesa contra candidíase invasiva disseminada, atuando tanto em blastoconídios intracelularmente, como em hifas extracelularmente (ROILIDES et al., 1992).

Segundo Mencacci et al. (1999), a capacidade de C. albicans estabelecer uma infecção disseminada no hospedeiro envolve a neutropenia como fator predisponente principal, enquanto a capacidade do fungo para persistir no organismo envolve, principalmente, depressão da imunidade celular adaptativa no hospedeiro.

Essas células são capazes de fagocitar microorganismos, incorporando-os em seus fagolisossomos e destruindo-os intracelularmente. Sãocélulasque, aolado de outros polimorfonucleares, produzem grandes quantidades de produtos tóxicos derivados de oxigênio (ROI), como peróxido de hidrogênio $\left(\mathrm{H}_{2} \mathrm{O}_{2}\right)$ e anion superóxido $\left(\mathrm{O}_{2}-\right)$ via sistema NADPH-oxidase. Esses produtos destroem os microrganismos por meio de diversos mecanismos, como liperoxidação de membrana e danos irreversíveis ao DNA (MARÓDI et al., 1998)

Neutrófilos possuem ainda mecanismos microbicidas não dependentes de oxigênio. Estes mecanismos envolvem as enzimas lisossomais, que são muito importantes nos tecidos onde a concentração de oxigênio é baixa e a cadeia respiratória não pode funcionar efetivamente. Dentre as hidrolases lisossomais, podemos citar as peroxidases, como: a lactoperoxidase, e a mieloperoxidase (MPO), que converte $\mathrm{O}_{2} \mathrm{O}_{2}$ em ácido hipocloroso (HOCL). A reação do HOCL com aminas primárias, ou outros compostos contendo nitrogênio, resulta na produção de monocloramina, outro poderoso agente oxidante gerado pelo sistema MPO- $\mathrm{H}_{2} \mathrm{O}_{2}$ (MARÓDI et al., 1998).

Em modelos de candidíase oral com depleção de neutrófilos, a doença agravou-se nos primeiros dias da infecção, mostrando a importância dessas células na defesa inicial do hospedeiro contra $C$. albicans (FARAH et al., 2001).

Células dendríticas são células eficientes na apresentação de antígenos, com capacidade de iniciar e direcionar a resposta imune (ROMANI, 2004).

As células dendríticas são capazes de reconhecer e internalizar tanto os blastoconídios, como as e hifas de C. albicans. Estas células expressam vários receptores, incluindo receptores para vários componentes do sistema complemento (CR), receptores para Fc (Fc $\gamma \mathrm{R})$ e receptores de reconhecimento padrão (PRRs), como os TLRs, receptor de Manose e DC-SIGN, e são as principais células conectoras da resposta imune inata e adaptativa (ROMAN; BISTONI; PUCCETTI, 2002). O reconhecimento das formas em levedura envolve a cooperação dos receptores de manose e do receptor CR3, enquanto a fagocitose de hifas envolve a cooperação dos receptores CR3 e Fcy. Uma vez dentro dos fagócitos, ocorre a degradação das leveduras, enquanto as hifas podem ser encontradas livres no citoplasma (ROMANI, 2004). Contudo, as leveduras podem sobreviver dentro do fagossoma se forem internalizadas via CR3. Jouault et al. (1998) haviam demonstrado que C. albicans possui moléculas que medeiam a interação via CR3, 
entretanto não se verifica a produção de óxido nítrico, quando a levedura era fagocitada por esta via. Esse fato possibilita a sobrevivência do fungo, enquanto a entrada da levedura pelo receptor de manose resulta na produção de citocinas pró-inflamatórias, incluindo IL-12, degradação do fungo e aumento de moléculas coestimulatórias (ROMANI; BISTONI; PUCCETTI, 2002).

\section{Moduladores da resposta imune}

Macrófagos nem sempre têm a sua capacidade fagocítica associada à sua capacidade de destruir microrganismos invasores. A fagocitose de $C$. albicans, quando não acompanhada de morte do fungo, pode favorecer a disseminação deste patógeno, pois os macrófagos não ativados, além de servir como veículos para a sua disseminação, protegem o fungo de outros mecanismos de resposta imune inata (VASQUEZ-TORRES; BALISH, 1997).

A atividade candidacida de macrófagos contra C. albicans e C. parapsilosis foi estudada, utilizandose fagócitos residentes peritoneais, estimulados com injeção de lipopolissacarídeos (LPS) ou obtidos de animais infectados pelo bacilo de Calmete-Guerin (BCG). Os macrófagos residentes mataram em torno de duas a três vezes menos $C$. albicans do que aqueles ativados por LPS ou BCG (SASADA; JOHNSTON JÚNIOR, 1980). As glicanas presentes na parede celular de $C$. albicans estimulam a produção de anion superóxido $\left(\mathrm{O}_{2}^{-}\right)$e de peroxinitrito, pelos macrófagos do exsudato peritoneal (VASQUEZTORRES; JONES-CARSON; BALISH, 1996).

A ativação dos macrófagos confere ao hospedeiro maior resistência à infecção, pelo aumento de sua capacidade fungicida, seja pelo aumento de receptores em sua superfície ou pela produção de substâncias de ação microbicida, sendo considerados como principais células efetoras contra infecção por patógenos intracelulares facultativos. Macrófagos ativados aumentam a produção de reagentes oxidativos intermediários
(ROI) e reagentes nitrogenados intermediários (RNI), e também aumentam a atividade microbicida, além de apresentarem aumento na produção de citocinas, como a interleucina 1 (IL-1), 6 (IL-6) e 8 (IL-8). Esta constitui-se um fator estimulador de colônias de macrófagos e granulócitos (GM-CSF) e TNF- $\alpha$, que podem estimular outras células ou os próprios macrófagos em uma atividade autócrina (MARÓDI; KORCHAK; JOHNSTON JÚNIOR, 1991; LANGERMANS et al., 1992).

A ativação de macrófagos pode ocorrer, também, pela ação de lectinas de origem vegetal, tais como a Concanavalina-A (Con-A) e a Jacalina (JCA) que agem sobre células T para produção de IFN- $\gamma$. Camundongos tratados previamente com Con-A ou JCA apresentaram aumento da atividade fagocítica e candidacida nos macrófagos da cavidade peritoneal e na sua capacidade de depurar o inóculo de $C$. albicans da cavidade peritoneal, diminuindo a disseminação do patógeno nas vísceras. Este efeito foi atribuído à ativação não específica de imunidade mediada por célula (FELIPE; BIM; SOMENSI, 1995; GAZIRI, et al., 1999; MORESCO et al., 2002; LOYOLA et al., 2002; CONCHON-COSTA, 2006, CONCHON-COSTA et al., 2007; LOYOLA et al., 2007). O mesmo efeito protetor foi verificado em camundongos previamente tratados com Con-A e inoculados, intraperitonealmente, com Serratia marcescens, (ARRAES et al., 1997), quando os macrófagos foram eficientes em fagocitar e destruir este patógeno. Segundo Bertram, Jilbert e Kotlarski (1997), a Con-A liga-se diretamente a carboidratos na região constante na molécula $\mathrm{MHC}$ e no receptor TCR das células $\mathrm{T}$ auxiliares e induz a ativação policlonal dos linfócitos, estimulando, entre outras citocinas, a liberação de IFN- $\gamma$. Quando estemitógeno é administrado pela veia da calda de camundongos, induz, no fígado, a expressão de mRNA de IL-2, IFN- $\gamma$ e TNF- $\alpha$ (OKAMOTO; KOBAYASHI, 1997). Contudo, Tagawa, Sekikawa e Iwakura (1997) e Trautwein et al. (1998) demonstraram que altas doses de Con-A causavam exacerbação da resposta Th1 e injúria no fígado, pelo excesso de produção 
de IFN- $\gamma$ e TNF- $\alpha$, os quais induzem à destruição dos hepatócitos por apoptose.

Loyola et al. (2002) demonstraram que a chegada precoce de neutrófilos na cavidade peritoneal de camundongos, observada 6 horas após administração de Con-A, foi importante para a redução do inóculo de $C$. albicans em animais infectados. Os autores demonstraram, também, que a catalase, administrada junto com C. albicans, inibia a redução do inóculo, sugerindo que a formação do ácido hipocloroso constitui um mecanismo muito importante na morte do fungo, e que, dentre os vários mecanismos candidacidas empregados, este era o mais importante. Para a formação do ácido hipocloroso, é necessária a produção de mieloperoxidase por neutrófilos, a qual necessita do substrato $\mathrm{H}_{2} \mathrm{O}_{2}$ e de cloro para a síntese deste composto.

\section{Citocinas envolvidas na resposta imune}

Embora, no geral, os fagócitos apresentem atividade antifúngica intrínseca, esta atividade pode ser melhorada por opsoninas e citocinas inflamatórias, em particular TNF- $\alpha$ e IFN- $\gamma$, as quais, por sua vez, podem ser moduladas por $C$. albicans.

Os níveis locais de citocinas são grandemente derivados de células $T$, assim, a resistência à candidíase requer a ação coordenada da defesa imune inata com a adaptativa (MARÓDI; KORCHAK; JOHNSTON JÚNIOR, 1991; GIL; GOZALBO, 2006). Dois grupos diferentes de células T CD4+ foram descritos (Th1 e Th2) e apresentam funções antagonistas. Células Th1 ativam os fagócitos para um estado fungicida, enquanto aquelas produzidas por células Th2 exacerbam a doença, por desativarem propriedades protetoras das células fagocíticas contra os fungos (ROMANI, 2004).

Células Th1 e Th2 desenvolvem-se a partir de um precursor comum célula T CD4+ "naive", cuja diferenciação, na candidíase murina, depende de vários fatores, como: cepa de C. albicans; resistência ou suscetibilidade do hospedeiro; via de infecção; produção de moléculas coestimuladoras; presença de citocinas no local (MENCACCI et al., 2000).

Camundongos geneticamente modificados suscetíveis $(\mathrm{BDA} / 2 \mathrm{Cr})$ e resistentes $(\mathrm{BALB} / \mathrm{cCr})$ a $C$. albicans foram utilizados para a avaliação do desenvolvimento de respostas Th1 e Th2. Quando os animais foram inoculados com cepas de baixa e alta virulência, os resistentes desenvolveram hipersensibilidade do tipo tardia (HTT), juntamente com produção de citocinas IL-2 e IFN- $\gamma$, baixa produção de anticorpos IgA, IgG1 e IgE, ausência de eosinofilia e alta taxa de sobrevivência, em comparação aos animais suscetíveis. Animais suscetíveis possuíam células $\mathrm{T}$ com alta produção de citocinas ligadas a um padrão tipo Th2, IL-4 e IL-10 e presença de eosinofilia, após poucos dias de infecção (ROMANI et al., 1993).

A função crucial de citocinas pró-inflamatórias na defesa contra $C$. albicans tem sido demonstrada pelo aumento de suscetibilidade de camundongos "knockout" para IL-2 e IFN- $\gamma$ (KÁPOSZTA et al., 1998; NETEA et al., 1999). Em contraste, citocinas anti-inflamatórias como IL-4 e IL-10 têm efeito imunossupressivo (TONNETII et al., 1995). Após a ativação de populações de leucócitos pela $C$. albicans, a liberação de citocinas pró-inflamatórias, como TNF- $\alpha$, Il- $1 \beta$, IL-6 e IFN- $\gamma$, é o primeiro passo para a ativação da resposta imune anticandidacida. Citocinas pró-inflamatórias ativam macrófagos e neutrófilos a fagocitar o fungo e a liberar radicais tóxicos de oxigênio e nitrogênio, eliminando, então, o patógeno invasor (KULBERG et al., 1993).

TNF- $\alpha$ é uma citocina de 17-kDa produzida em resposta a infecção fúngica na fase inicial da infecção estimulada por C. albicans (VECCHIARELLI et al., 1991). Macrófagos, neutrófilos, células endoteliais, fibroblastos e linfócitos T e B secretam TNF- $\alpha$, contudo, os macrófagos são as principais fontes de TNF- $\alpha$ in vivo. Esta citocina exerce várias atividades biológicas incluindo proliferação e diferenciação celular, apoptose, citotoxidade, inflamação e 
imunomodulação (DEROUICH-GUERGOUR et al., 2001).

Estudos in vitro demonstraram que o TNF- $\alpha$ pode ativar macrófagos e neutrófilos, levando ao aumento do "burst oxidativo", da fagocitose e da atividade fungicida (DJEU et al., 1986; FERRANTE, 1989; JUPIN; PARANT; CHEDIDS, 1989; SHALABY et al., 1985). TNF- $\alpha$ também estimula a expressão ou medeia a atividade de várias outras moléculas envolvidas na defesa contra C.albicans, por exemplo, células endoteliais respondem à infecção in vitro por C. albicans expressando E-selectina, molécula de adesão vascular celular (VCAM-1), molécula de adesão intercelular (ICAM-1), e secretando IL-8 e fator ativador de plaquetas (PAF), que participam no recrutamento de leucócitos no local da infecção (OROZCO; ZHOU; FILLER, 2000; IM; CHOI; $\mathrm{KO}, 1997)$.

A função do TNF- $\alpha$, na proteção do hospedeiro, em candidíase disseminada, tem sido demonstrada por estudos com camundongos cujas cópias do gene de TNF- $\alpha$ foram deletadas. Quando desafiados por via intravenosa, com $C$. albicans, todos os camundongos $\mathrm{TNF}-\alpha^{-/-}$morreram, enquanto todos os do tipo selvagem sobreviveram (MARINO; DUNN; GRAIL, 1997). Na candidíase orofaringea, Farah et al. (2006) verificaram, em infecção experimental oral, que camundongos TNF- $\alpha^{-/}$, apresentaram aumento na severidade da infecção.

Por outro estudo, a neutralização de TNF- $\alpha$ por anticorpos anti TNF- $\alpha$ aumentou a severidade no curso de infecção experimental, pois rins e baço apresentavam-se densamente colonizados, o que diminuiu a sobrevida após a infecção (LOUIE; BALTCH; SMITH, 1994).

TNF- $\alpha$ induz ainda à produção de outras citocinas, como IL-6 e IL-1, que podem participar na resposta do hospedeiro no curso da infecção sistêmica por $C$. albicans. A administração de TNF- $\alpha$ exógeno aumenta a resistência à infecção, enquanto a inibição desta citocina endógena diminui a resistência (LOUIE; BALTCH; SMITH, 1994)
A liberação de TNF- $\alpha$ por macrófagos, durante a fase inicial da resposta inflamatória ao fungo, atrai e ativa neutrófilos para um estado efetor antifúngico (DIAMOND; LYMAN; WYSONG, 1991). Mencacci et al. (1998) demonstraram que TNF- $\alpha$ também era requerido para a expressão ótima de moléculas coestimulatórias nas células fagocíticas e para a resposta a IL-12 nas células CD4+. Contudo, durante a fase mais tardia da infecção, quando o fungo prolifera rapidamente, níveis muito elevados de TNF- $\alpha$ afetam negativamente a rede de citocinas, resultando, às vezes, em choque séptico (WALLEY et al., 1996).

Ohmura et al. (2001), em modelo experimental de infecção intraperitoneal, verificaram que camundongos previamente estimulados com um polissacarídeoligadoà proteína(PSK), apresentavam maior taxa de sobrevivência contra infecção letal por $C$. albicans, e o mecanismo protetor era devido, principalmente, à produção de TNF- $\alpha$.

Conchon-Costa et al. (2007) demonstraram aumento no nível de TNF- $\alpha$ no sobrenadante das células do exsudato peritoneal, fígado e baço, em camundongos tratados com Con-A, os autores obtiveram $100 \%$ de sobrevivência nos animais tratados, enquanto sobreviveram apenas $20 \%$ dos animais do grupo controle.

Entre as citocinas do tipo Th1, IFN- $\gamma$ é um potente ativador de fagócitos (NETEA et al., 1999), e atuam, também, na diferenciação das células. Th. Romani et al. (1992) verificaram que a neutralização de IFN- $\gamma$ impediu o desenvolvimento da reposta protetora Th1. Neutrófilos tratados com IFN- $\gamma$ aumentaram, significativamente, a explosão metabólica oxidativa em resposta a pseudo-hifas e hifas de $C$. albicans, opsonizadas ou não, e a blastoconídios opsonizados, aumentando a produção de peróxido de hidrogênio (STEVENHAGEN; VAN FURTH, 1993) e induzindo à produção de óxido nítrico por macrófagos (CENCI et al., 1993). A produção dessa citocina influencia a sobrevida de camundongos na candidíase invasiva experimental (KÁPOSZTA et 
al., 1998; YAMAMOTO; KLEIN; FRIEDMAN, 1997), contudo, a produção dessa citocina por tempo prolongado pode levar à superprodução de TNF- $\alpha$ (VASQUEZ-TORRES; BALISH, 1997).

A citocina IL-12, segundo Romani et al. (1994a), também tem um papel essencial na expansão preferencial de células protetoras Th1. Os autores verificaram que transcritos de IL-12 eram constantemente expressos em macrófagos de camundongos resistentes, mas não de camundongos suscetíveis a $C$. albicans. Utilizando anticorpos neutralizadores de IL-12, Romani et al. (1994b) verificaram que camundongos resistentes perdiam a capacidade de desenvolver uma resposta protetora Th1 com produção de citocinas Th2 como IL-4.

Outras citocinas, como IL-1, IL-8, estão envolvidas na resposta a $C$. albicans. Van't Wout et al. (1988) demonstraram que o tratamento profilático de camundongos com IL-1 $\beta$ aumenta o número de neutrófilos no tecido infectado, assim como, a resistência na candidíase sistêmica, e que a administração de IL-1 $\beta$ e IL-1 $\alpha$ protege camundongos neutropênicos da infecção letal por C. albicans.

Citocinas do tipo Th2 como IL-4 e IL-10 estão relacionadas à progressão e à exacerbação da candidíase (CENCI et al., 1993). A IL 10 foi primeiramente descrita como uma citocina que apresentava potente atividade antiinflamatória (MOSMANN, 1994), sendo o principal inibidor da resposta inata e inflamatória e um imunoregulador do desenvolvimento de células Th. Vários autores têm demonstrado que a exposição de fagócitos a essa citocina inibe a síntese de citocinas pró-inflamatórias e a liberação de reativos intermediários de oxigênio e nitrogênio. Bogdan, Vodovotz e Nathan (1991) demonstraram que IL-10 exerce função na resposta inflamatória aguda. Os autores verificaram que macrófagos estimulados com LPS e/ou IFN- $\gamma$ diminuíram, significativamente, a produção das citocinas IL-1, IL-6 e TNF- $\alpha$. Camundongos susceptíveis $(\mathrm{BDA} / 2)$ inoculados com uma cepa atenuada de $C$. albicans apresentaram altos níveis de produção de IL-10, inibição de morte do fungo via óxido nitrico (ON) e desenvolvimento de resposta Th2. Quando esta citocina era neutralizada ocorria aumento na produção de ON (ROMANI et al., 1994c).

Ding e Shevach (1992) demonstraram que esta citocina não promove diretamente o desenvolvimento de Th2, mas atua nas células indiretamente, reduzindo a expressão de moléculas coestimuladoras e a produção de citocinas por células da imunidade inata, como a inibição da produção de IL-12 durante o estímulo antigênico primário, o que, por sua vez, inibe a secreção de IFN- $\gamma$ prevenindo, subseqüentemente, o desenvolvimento de resposta imune mediada por Th1. Del Sero et al. (1999), em experimentos com camundongos deficientes em IL-10, demonstraram ser estes mais resistentes à infecção por C. albicans do que os camundongos selvagens. O aumento na resistência estava associado à regulação da resposta antifúngica inata $\mathrm{e}$ Th1, com aumento da produção de IL-12, ON, TNF- $\alpha$ e IFN- $\gamma$ por células T CD4+.

Contudo, a produção de níveis fisiológicos de IL10 é necessária para a proteção ideal da resposta a $C$. albicans, uma vez que inibe a síntese excessiva de citocinas pró-inflamatórias por células inflamatórias (DAÍ; KOHOLER; BROMBACHER, 1997).

Células T CD8+ não são consideradas efetivas no mecanismo de defesa contra C. albicans. Contudo, Beno, Stover e Mathews (1995) demostraram que essas células, obtidas de camundongos "naive" e estimuladas com IL-2, possuíam a capacidade de inibir o crescimento de C. albicans in vitro.

\section{Anticorpos na imunidade a Candida albicans}

Não há evidências que anticorpos e o sistema complemento possam mediar a lise de C. albicans, contudo, pacientes com candidíase disseminada podem apresentar anticorpos específicos no soro (ODDS, 1988). Estudos têm mostrado que anticorpos 
com diferentes especificidades apresentam diferentes graus de proteção contra candidíase e podem aumentar a resistência nas infecções com C. albicans. A administração de manana do fungo, encapsulada em lipossomos, resultou na produção de anticorpos que conferiram resistência à candidíase disseminada (HAN; CUTLER, 1995). Morangues et al. (2003) descreveram um anticorpo monoclonal contra manoproteina que apresentou três diferentes atividades anti $C$. albicans: inibição de aderência, inibição na formação de tubo germinativo e atividade candidacida. Sevilla et al. (2006) demonstraram por meio de um modelo murino de candidíase invasiva, que a atividade candidacida de macrófagos era fortemente aumentada quanto $C$. albicans era opsonizada com um anticorpo monoclonal (C7).

No soro de pacientes recuperados de candidíase disseminada, foram encontrados anticorpos contra proteína hsp90 de C. albicans (MATTHEWS et al., 1991; MATTHEWS; BURNIE, 1992) e esses anticorpos protegeram camundongos contra a doença disseminada. Segundo Lee et al. (2003), na defesa do hospedeiro contra $C$. albicans, o desenvolvimento da resposta Th1 é critica e a presença de anticorpos específicos pode aumentar esse mecanismo de defesa por opsonizar o patógeno e facilitar a fagocitose.

\section{Considerações finais}

Um claro entendimento dos diferentes mecanismos de defesa envolvidos na infecção por C. albicans é essencial para o desenvolvimento de estratégias tanto para a prevenção e controle, como para o tratamento das infecções por este fungo. Conforme o exposto, mecanismos da resposta imune inata e adquirida formam um sistema integrado de defesa do hospedeiro, no qual numerosas células e moléculas funcionam coletivamente. A resposta imune inata é de suma importância na resolução da doença, além de influenciar o tipo de resposta específica que se desenvolverá subseqüentemente.
Igualmente, a resposta imune adquirida pode intervir durante a imunidade inata, uma vez que citocinas produzidas por células Th modulam a ação de células efetoras. Os fagócitos participam em ambas as interações e a utilização de moduladores da resposta imune produzem efeitos antiinfecciosos por modificar a resposta do hospedeiro a microrganismos patogênicos.

\section{Referências}

ADEREM, A.; UNDERHILL, D. M. Mecanisms of phagocytosis in macrophages. Annual Review of Immunology, Palo Alto, v. 17, p. 593-623, 1999.

ARRAES, S. M. A. A.; GAZIRI, L. C. J.; VIDOTTO, M. C.; SARIDAKIS, H. O.; FELIPE, I. Pre-treament with concanavalin-A increases resistence of mice to peritoneal infection by Serratia marcescens. Journal of Medical Microbiology, London, v. 46, n. 1, p. 251-255, 1997.

BENO, A. G.; STOVER, A. G.; MATHEWS H. L. Growth inhibition of Candida albicans hyphae by CD8+ lymphocytes. Journal of Immunology, Baltimore, v. 154, n. 10 , p. 5273-5281, 1995.

BERTRAM, E. M.; JILBERT, A. R.; KOTLARSKI, I. Optimization of an in vitro assay which measures the proliferation of Duck T Lymphocytes from peripheral blood in response to stimulation with PHA and CON-A. Developmental \& Comparative Immunology, New York, v. 21, n. 3, p. 299-310, 1997.

BOGDAN, C.; VODOVOTZ, Y.; NATHAN, C. Macrophage deactivation by Interleukin 10. Journal of Experimental Medicine, New York, v. 175, p. 1547-1555, 1991.

BROWN, G. D.; GORDON, S. A new receptor for betaglucans. Nature, London, v. 413, n. 1, p. 36-37, 2001.

CENCI, E.; ROMANI, L.; MENCACCI, A.; SPACCAPELO, R.; SCHIAFFELLA, E.; PUCCETTI, P.; BISTONI, F. Interleukin-4 an inerleukin-10 inhibit nitric oxide-dependent macrophage killing of Candida albicans. European Journal of Immunology, Weinheim, v. 23, n. 5, p. 1034-1038, 1993.

CONCHON-COSTA, I. Baixa dose de Concanavalina-A aumenta a imunidade inata e previne injúria no figado em camundongos infectados com Candida albicans. 2006. Tese. (Doutorado em Microbiologia) - Universidade Estadual de Londrina, Londrina. 
CONCHON-COSTA, I.; LOOLA, W.; GAZIRI, L. C. J.; CUSTÓDIO, L. A.; FELIPE, I. Low dose of Concanavalin-A enhance innate immune response and prevents liver injur in mice infected with Candida albicans. FEMS Immunology and Medical Microbiology, Amsterdam, v. 49, n. 7, p. 330-336, 2007.

D'OSTIANI, C. F.; DEL SERO, G.; BACCI, A.; MONTAGNOLI, C.; SPRECA, A.; MENCACCI, A.; RICCIARDI-CASTAGNOLIC, P.; ROMANIA, L. Dendritic cells discriminate between yeast and hyphae of the fungus Candida albicans: implications for initiation of T Helper immunity in vitro and in vivo. Journal of Experimental Medicine, New York, v. 191, n. 10, p. 1661-1674, 2000.

DAÍ, W.; KOHOLER, G.; BROMBACHER, F. Both innate and acquired immunity to Listeria monocytogenes infection are increased in IL-10-deficient mice. Journal of Immunology, Baltimore, v. 158, n. 5, p. 2259-2267, 1997.

DELSERO,G.; MENCACCI,A.; CENCI,E.; D’OSTIANI, C. F.; MONTAGNOLI, C.; BACCI, A.; MOSCI, P.; KOPF, M.; ROMANI, L. Antifungal type 1 responses are upregulated in IL-10-deficient mice. Microbes and Infection, Paris, v. 1, n. 14, p. 1169-1180, 1999.

DEROUICH-GUERGOUR, D.; BRENIER-PINCHART, M.; AMBROISE-THOMAS, P.; PELLOUX, H. Tumor necrosis factor $\alpha$ receptors: role in the physiopathology of protozoan parasite infections. International Journal for Parasitology, Oxford, v. 31, n. 8, p. 763-769, 2001.

DIAMOND, R. D.; LYMAN, C. A.; WYSONG, D. R. Disparate effects of interferon- $\gamma$ and tumor necrosis factor- $\alpha$ on early neutrophil respiratory burst and fungicidal response to Candida albicans hyphae in vitro. Journal of Clinical Investigator, Berlin, v. 82, n. 2, p. 711-720,1991.

DING, L.; SHEVACH, E. M. IL-10 inhibits mitogeninduced $\mathrm{T}$ cell proliferation by selectively inhibiting macrophage costimulatory function. Journal of Immunology, Baltimore, v. 148, n. 10, p. 3133-3139, 1992.

DJEU, J. Y.; BLANCHARD, D. K.; HALKIAS, D.; FRIEDMAN, H. Growth inhibition of Candida albicans by human polymorphonuclear neutrophils: activation by interferon-gamma and tumor necrosis factor. Journal of immunology, Baltimore, v. 137, n. 9, p. 2980-2984,1986.

FARAH, C. S.; ELAH, S.; PANG, G.; GOTJAMANOS, T.; SEYMOUR, G. J.; CLANCY, R. L.; ASHAMN, R. B. T. T cells augment monocyte and neutrophil function in host resistence against oropharyngeal candidiasis. Infection and Immunity, Washington, v. 69, n. 10, p. 6110-6118, 2001.
FARAH, C. S.; HU, Y.; RIMINTON, S.; ASHMAN, R. B. Distinct roles for interleukin-12p40 and tumour necrosis factor in resistance to oral candidiasis defined by genetargeting. Oral Microbiology Immunology, Copenhagen, v. 21, n. 4, p. 252-255, 2006.

FELIPE, I.; BIM, S.; SOMENSI, C. C. Increased clearance of Candida albicans from the peritoneal cavity of mice pre-treated with concanavalin-A or jacalin. Brazilian Journal of Medical and Biological Research, Ribeirão Preto, v. 28, n. 4, p. 477-483, 1995.

FERRANTE, A. Tumor necrosis factor alfa potentiates neutrophil antimicrobial activity: Increased fungicidal activity against Toulopsis glabrata and Candida albicans and associated increases in oxygen radical production and lysosomal enzyme release. Infection and Immunity, Washington, v. 57, n. 7, p. 2115-2122, 1989.

FIDEL JÚNIOR, P. L. The protective immune response against vaginal candidiasis: lessons learned from clinical studies and animal model. International Reviews of Immunology, Philadelphia, v. 21. n. 6, p. 515-548, 2002.

GANTNER, B. N.; SIMMONS, R. M.; UNDERHILL, D. M. Dectin-1 mediates macrophage recognition of Candida albicans yeast but not filaments. The EMBO Journal, Oxford, v. 24, n. 6, p. 1277-1286, 2005.

GAZIRI, G.; GAZIRI, L. C. J.; KIKUCHI, R.; SCANAVACCA, J.; FELIPE, I. Phagocytosis of Candida albicans by concanavalin-A actived peritoneal macrophages. Medical Mycology, Oxford, v. 37, n. 3, p. 195-200, 1999.

GIL, M. L.; GOZALBO, D. TLR2, but not TLR4, triggers cytokine production by murine cells in response to Candida albicans yeasts and hyphae. Microbes and Infection, Paris, v. 8, n. 8, p. 2299-2304, 2006.

GORDON, S. The role of the macrophage in immune regulation. Immunologic Research, Basel, v. 149, n. 7-8, p. $685-688,1998$.

HAN, Y.; CUTLER, J. E. Antibody response that protects against disseminated candidiasis. Infection and Immunity, Washington, v. 63, n. 7, p. 2714-2719, 1995.

IM, S. Y.; CHOI, J. H.; KO, H. M. A protective role of platelet-activating factor murine candidiasis. Infection and Immunity, Washington, v. 65, n. 4, p. 1321-1326, 1997.

ISMAIL, N.; OLANO, J. P.; FENG, H.; WALKER, D. $\mathrm{H}$. Current status of immune mechanisms of killing of intracellular microorganims. FEMS Microbiology Letters, Amsterdam, v. 207, n. 2, p. 111-120, 2002. 
JOUAULT, T.; FRADIN, C.; TRINEL, P. A.; BERNIGAUD, A.; POULAIN, D. Early signal transduction induced by Candida albicans in macrophages through shedding of a glycolipid. Journal of Infectious Diseases, Chicago, v. 178, n. 3, p. 792-802, 1998.

JUPIN, C.; PARANT, M.; CHEDIDS, L. Involvement of reactive oxygen metabolites in the candidacidal activity of human neutrophils stimulated by muramyl dipeptide or tumor necrosis factor. Immunobiology, Jena, v. 180, n. 1,p. 68-79, 1989.

KÁPOSZTA, R.; TREE, P.; MARÓDI, L.; GORDON, S. Characteristics of invasive candidiasis in gama interferonand interleukin-4- deficient mice: role of macrophage in host defense against Candida albicans. Infection and Immunity, Washington, v. 66, n. 4, p. 1708-1717, 1998.

KARBASSI, A.; BECKER, J. M.; FOSTER, J. S.; MOORE, R. N. Enhanced killing of Candida albicans by murine macrophages treated with macrophage colonystimulating factor: evidence for augmented expression of mannose receptors. Journal of Immunology, Baltimore, v. 139, n. 2, p. 417-421, 1987.

KULBERG, B. J.; VAN'T WOUT, J. W.; HOOGSTRATEN, C., VAN FURTH, R. Recombinant interferon-g enhances resistance to acute disseminated Candida albicans infection in mice. Journal of Infectious Diseases, Chicago, v. 168, n. 2, p. 436-443, 1993.

LANGERMANS, J. A. M.; VANDERHULST, M. E. B.; NIBBERING, P. H.; HIEMSTRA, P. S.; FRANSEN, L.; VAN FURTH, R. IFN-induced L-arginine-dependent toxoplasmastatic activity in murine peritoneal macrophages is mediated by endogenous tumor necrosis factor- $\alpha$. Journal of Immunology, Baltimore, v. 148, n. 2, p. 568-574, 1992.

LEE, S. J.; ZHENG, N.; CLAVIJO, M.; NUSSENZWEIG, M. C. Normal host defense during systemic candidiasis in mannose receptor-deficient mice. Infection and Immunity, Washington, v. 71, n. 1, p. 437-445, 2003.

LORENZ, M. C.; FINK, G. R. Life and death in a macrophage: role of the glyoxylate cycle in virulence. Eukaryotic Cell, Washington, v. 1, n. 5, p. 657-662, 2002.

LOUIE, A.; BALTCH, A. L.; SMITH, R. P. Tumor necrosis factor alpha has a protective role in a murine model of systemic candidiasis. Infection and Immunity, Washington, v. 62, n. 7, p. 2761-2772, 1994.

LOYOLA, W.; CONCHON-COSTA, I.; GAZIRI, L. J.; NOMIZO, A.; FELIPE, I. Phagocytosis of Candida albicans from mice pretreated with extract of Artocarpus intergrifolia is mediated by Dectin-1 receptors. In:
INTERNATIONAL CONGRESS OF IMMUNOLOGY, 13., 2007, Rio de Janeiro, RJ. Anais... Rio de Janeiro: UFRJ, 2007.

LOYOLA, W.; GAZIRI, D. A.; GAZIRI, L. C. J.; FELIPE, I. Concanavalin-A enhances phagocytosis and killing of Candida albicans by mice peritoneal neutrophils and macrophages. FEMS Immunology and Medical Microbiology, Amsterdam, v. 33, n. 3, p. 201208, 2002.

MARINO, M.W.;DUNN,A.; GRAIL, D. Characterization of Tumor necrosis factor-deficient mice. Proceedings of the National Academy of Sciences of the United States of America, Washington, v. 94, n. 15, p. 8093-8098, 1997.

MARÓDI, L.; JOHNSTON JÚNIOR, R. B. Enhancement of macrophage candidacidal activity by interferon- $\gamma$. Immunodeficiency, Yverdon, v. 4, n. 1-4, p. 181-185, 1993.

MARÓDI, L.; KORCHAK, H. M.; JOHNSTON JÚNIOR, R. B. Mechanisms of host defense against Candida species. I. Phagocitosis by monocytes and monocyte-derived macrophages. Journal of Immunology, Baltimore, v. 146, n. 8, p. 2783-2789, 1991.

MARÓDI, L.; TOURNAY, C.; KÁPOSZTA, R.; JOHNSTON JÚNIOR, R. B.; MOGUILEVSKY, N. Augmentation of human macrophage candidacidal capacity by recombinant human myeloperoxidase and granulocyte-macrophage colony-stimulating factor. Infection and Immunity, Washington, v. 66, n. 6, p. 27502754, 1998.

MATTHEWS, R. C.; BURNIE, J. P The role of hsp 90 in fungal infection. Immunology Today, Cambridge, v. 13, n. 9 , p. $345-348,1992$.

MATTHEWS, R. C.; BURNIE, J. P.; HOWAT, D.; ROWLAND, T.; WALTON, F. Autoantibody to heatshock protein 90 can mediate protection against systemic candidosis. Immunology, Oxford, v. 74, n. 1, p. 20-24, 1991.

MENCACCI, A.; CENCI, E.; BACCI, A.; MONTAGNOLI, C.; BISTONI, F.; ROMANI, L. Cytokines in candidiasis and aspergillosis. Current pharmaceutical biotechnology, Hilversum, v. 1, n. 3, p. 235-251, 2000.

MENCACCI, A.; CENCI, E.; DEL SERO, G.; D’OSTIANI, C. F.; MONTAGNOLI, C.; BACCI, A.; BISTONI,.F. Innate and adaptative immunity to Candida albicans: A new view of an old paradigma. Revista Iberoamericana de Micologia, Barcelona, v. 16, n. 1, p. 4-7, 1999. 
MENCACCI, A.; CENCI, E.; DEL SERO, G.; D'OSTIANI, C. F.; MOSCI, P.; TRINCHIERI, G.; ADORINI, L.; ROMANI, L. IL-10 is required for development of protective Th1 responses in IL-12 deficient mice upon Candida albicans infection. Journal of Immunology, Baltimore, v. 161, n. 11, p. 6228-6237, 1998 .

MORANGUES, M. D. M. J.; OMAETXEBARRIA, N.; ELGUEZABAL, M. J.; SEVILLA, S.; CONTI, L.; POLONELL, I.; PONTÓN. J. A monoclonal antibody directed against a Candida albicans cell wall mannoprotein exerts three anti- $C$. albicans activities. Infection and Immunity, Washington, v. 71, n. 9, p. 5273 5279, 2003.

MORESCO, T. R.; GAZIRI, L. C. J.; YASUMOTO, Y.; FELIPE, I. Phagocytic and candidacidal activies of macrophages from suckling and adult mice pretreated with concanavalin-A. Medical Mycology, Oxford, v. 40, n. 4, p. 393-397, 2002.

MOSMANN, T. R. Properties and functions of interleukin-10. Advances in Immunology, New York, v. 56, n. 1, p. 1-26, 1994.

NETEA, M. G.; GOW, N. A. R.; MUNRO, C.A.; BATES, S.; COLLINS, C.; FERWERDA, G.; HOBSON, R. P.; BERTRAM, G.; HUGHES, H. B.; JANSEN, T.; JACOBS, L.; BUURMAN, E. T.; GIJZEN, K.; WILLIAMS, D. L.; TORENSMA, R.; McKINNON, A.; MacCALLUM, D. M.; ODDS, F. C.; VAN DER MEER, J. W. M.; BROWN, A. J. P.; KULBERG, B. J. Immune sensing of Candida albicans requires cooperative recognition of mannans and glucans by lectin and toll-like receptors. Journal of Clinical Investigation, New York, v. 116, n. 6, p. 16421650, 2006.

NETEA, M. G.; SUTMULLER, R.; HERMANN, C.; VAN DER GRAAF, C. A. A.; VAN DER MEER, J. W. M.; VAN KRIEKE, J. H.; HARTUNG, T.; ADEMA, G.; KULBERG, B. J. Toll-like receptor 2 suppresses immunity against Candida albicans through induction of IL-10 and regulatory T cells. Journal of Immunology, Baltimore, v. 172, n. 6, p. 3712-3718, 2004.

NETEA, M. G.; VAN DER GRAAF, C. A. A.; VONK, A. G.; VERSCHUEREN, I.; VAN DER MEER, J. W. M.; KULBERG, B. J. The role of Toll-like receptor (TLR) 2 and TLR 4 in the host defense against disseminated candidiasis. Journal of Infectious Diseases, Chicago, v. 185, n. 10, p. 1483-1489, 2002.

NETEA, M. G.; VAN TITS, L. H. J.; CURFS, J. A. H. J.; AMITO, F.; MEIS, J. F. G. M.; VAN DER MEER, J. W. M.; KULLBERG, B. J. Increased susceptibility of TNF- $\alpha$
LT $\alpha$ double knockout mice to systemic candidiasis through defective recruitiment of neutrophils and phagocytosis of Candida albicans. Journal of Immunology, Baltimore, v. 163, n. 3, p. 1498-1505, 1999.

ODDS, F. C. Candida and candidosis. London: Bailiere Tindall, 1988.

OHMURA, Y.; MATSUNAGA, K.; MOTOKAWA, I.; SAKURAI, K.; ANDO, T. Protective effects of a proteinbound polysaccharide, PKS, on Candida albicans infection in mice via tumor necrosis factor- $\alpha$ induction. International Immunopharmacol, Amsterdam, v. 1, n. 9-10, p. 1797-1811, 2001.

OKAMOTO, T.; KOBAYASHI, T. Effects of concanavali-A on cytokine mRNA expression in mouse liver. Japanese Journal of Pharmacology, Kyoto, v. 75, n. 2, p. 199-201, 1997.

OROZCO, A. S.; ZHOU, X.; FILLER, S. G. Mechanisms of the proinflammatory response of endothelial cells to Candida albicans infection. Infection and Immunity, Washington, v. 68, n. 3, p. 1134-1141, 2000.

QIAN, Q.; JUTILA, M. A.; ROOIJEN, N. V.; CUTLER, J. E. Elimination of mouse splenic macrophages correlates with increased susceptibility to experimental disseminated candidiasis. Journal of Immunology, Baltimore, v.152, n. 10, p. 5000-5008, 1994.

ROILIDES, F.; UHLIG, K.; VENZON, D.; PIZZO, P. A.; WALSH, T. J. Neutrophil oxidative burst in response to blastoconidia and pseudohyphae of Candida albicans: augmentation by granulocyte colony-stimulating factor and interferon-gamma. Journal of infectious diseases, Chicago, v. 166, n. 3, p. 668-673, 1992.

ROMANI, L. Immunity to fungal infections. Nature reviews: Immunology, London, v. 4, n. 1, p. 1-13, 2004.

ROMANI, L.; BISTONI, F.; PUCCETTI, P. Fungi, dendritic cells and receptors: a host perspective of fungal virulence. Trends in Microbiology, Cambridge, v. 10, n. 11, p. 508-514, 2002.

ROMANI, L.; CENCI, E.; MENCACCI, A.; SPACCAPELO, R.; GROHMANN, U.; PUCCETTI, P.; BISTONI, F. Gamma interferon modifies CD4+ subset expression in murine candidiasis. Infection and Immunity, Washington, v. 60, n. 11, p. 4950-4952, 1992.

ROMANI, L.; MENCACCI, A.; CENCI, E.; SPACCAPELO, R.; MOSCI, P.; PUCCETTI, P.; BISTONI, F. $\mathrm{CD}^{+}$subset expression in murine candidiasis. Journal of Immunology, Baltimore, v. 150, n. 3, p. $925-931,1993$. 
ROMANI, L.; MENCACCI, A.; TONNETTI, L.; SPACCAPELO, R.; CENCI, E.; WOLF, S.; PUCCETTI, P.; BISTONI, F. Interleukin-12 but not interferon- $\boldsymbol{\gamma}$ production correlates with induction of $\mathrm{T}$ helper type-1 phenotype in murine candidiasis. European Journal of Immunology, Weinheim, v. 24, n. 4, p. 909-915, 1994a.

ROMANI, L.; MENCACCI, A.; TONNETTI, L.; SPACCAPELO, R.; CENCI, E.; WOLF, S.; PUCCETTI, P.; WOLF, S. F.; BISTONI, F. IL-12 is both requires and prognostic in vivo for $\mathrm{T}$ heper type I differentiation in murine candidiasis. Journal of Immunology, Baltimore, v. 152, n. 11, p. 5167-5175, 1994 b.

ROMANI, L.; PUCCETTI, P.; BISTONI, F. Biological role of Th cell subsets in candidiasis. Chemical Immunology, Basel, v. 63, p. 115-137, 1996.

ROMANI, L.; PUCCETTI, P.; MENCACCI, A.; CENCI, E.; SPACCAPELO, R.; TONNETTI, L.; GROHMAN, U.; BISTONI, F. Neutralization of IL-10 up-regulates nitric oxide production and protects susceptible mice from challenge with Candida albicans. Journal of Immunology, Baltimore, v. 152, n. 7, p. 3514-3521, 1994c.

SANTOS, A. A.; SÁ, E. A. C.; GAZIRI, L. C. J.; FELIPE, I. Treatment of serum with supernatants from cultures of Candida albicans reduces its serum-dependent phagocytosis. Brazilian Journal of Microbiology, São Paulo, v. 33, n. 1, p. 79-83, 2002.

SASADA, M.; JOHNSTON JÚNIOR, R. B. Macrophage microbicidal activity correlation between phagocytosisassociated oxidative metabolism and the killing of Candida by macrophages. Journal of Experimental Medicine, New York, v. 152, n. 1, p. 85-98, 1980.

SENET, J. M. Risk factors and physiopathology of candidiasis. Revista Iberoamericana de Micologia, Barcelona, v. 14, n. 1, p. 6-13, 1997.

SEVILLA, M. J.; ROBLEDO, B.; REMENTERIA, A; MORAnGUES, M. D.; PONTÓN, J. A Fungicidal Monoclonal Antibody Protects against Murine Invasive Candidiasis. Infection and Immunity, Washington, v. 74, n. 5, p. 3042-3045, 2006.

SHALABY, M. R.; AGGARWAL, B. B.; RINDERKNECHT, E.; SVEDERSKY, L. P.; FINKLE, B. S.; PALLADINO JÚNIOR., M. A. Activation of human polymorphonuclear neutrophil functions by interferon-gamma and tumor necrosis factors. Journal of Immunology, Baltimore, v. 135, n. 3, p. 2069-2073, 1985.

STEVENHAGEN, A.; VAN FURTH, R. Interferongama activates the oxidative killing of Candida albicans by human granulocytes. Clinical and Experimental Immunology, Oxford, v. 91, n. 1, p. 170-175, 1993.
TAGAWA, Y.; SEKIKAWA, K.; IWAKURA, Y. Suppression of concanavalin A-induced hepatitis in IFN- $\gamma$ -/- mice, but not in TNF- $\alpha^{-/-}$mice. Journal of Immunology, Baltimore, v. 159, n. 3, p. 1418-1428, 1997.

TONNETII, L.; SPACCAPELO, R.; CENCEI, E.; MENCACCI, A.; PUCCETTI, P.; COFFMAN, R. L.; BISTONI, F.; ROMANI, L. Interleukin-4 and 10 exacerbat candidiasis in mice. European Journal of Immunology, Weinheim, v. 25, n. 6, p.1559-1565, 1995.

TRAUTWEIN, C.; RAKEMANN, T.; MALEK, N. P.; PLIIMPE, J.; TIEGS, G.; MANNS, M. P. Concanavalin A-induced liver injury triggers hepatocyte proliferation. Journal of Clinical Investigation, New York, v. 101, n. 9, p. 1960-1969, 1998.

UNDERHILL, D. M.; OZINSKY, A. Toll-like receptor: key mediators of microbe detection. Current Opinion in Immunology, London, v. 14, n. 1, p. 103-110, 2002.

VAN DE GRAAF, C. A.; NETEA, M. G.; VERSCHUEREN, I.; VAN DER MEER, J. W. M.; KULBERG, B. J. Differential cytokine production and toll-like receptor signaling pathways by Candida albicans blastoconidia and hyphae. Infection and Immunity, Washington., v. 73, n. 5, p. 7458-7464, 2005.

VAN'T WOUT, J. W.; LINDE, L.; LEIJ, P. C. J.; VAN FURTH, R. Contribuition of granulocytes and monocytes to resistance against experimental disseminated $C$. albicans infection. European Journal of Clinical Microbiology \& Infectious Diseases, Wiesbaden, v. 7, n. 6, p. 736-741, 1988.

VASQUEZ-TORRES, A.; JONES-CARSON, J.; BALISH, E. Peroxinitrite contributes to the candidacidal activity of nitric oxide-producing macrophages. Infection and Immunity, Washington, v. 64, n. 8, p. 3127-3133, 1996.

VASQUEZ-TORRES, A; BALISH, E. Macrophages in resistence to candidiasis. Microbiology and Molecular Biology Reviews, New York, v. 61, n. 3, p. 170-192, 1997.

VECCHIARELLI, A.; PULITI, M.; TOROSANTUCCI, A.; CASSONE, A.; BISTONI, F. In vitro production of tumor necrosis factor by nurine splenic macrophages stimulated with mannoprotein constituents of Candida albicans cell wall. Cellular Immunology, New York, v. 134, n. 1, p. 65-76, 1991.

VILLAMÓN,E.;GOZALBO,D.; ROIG,P.;O’CONNOR, J. E.; FRADELIZI, D.; GIL, M. L. Toll-like recptor-2 is essential in murine defenses against Candida albicans infections. Microbes and Infection, Paris, v. 6, n. 1, p. 1-7, 2004. 
WALLEY, K. R.; LUKACS, N. W.; STANDIFORD, T. J.; STRIETER, R. M.; KUNKEL, S. L. Balanced of inflammatory cytokines related to severity and mortality of murine sepsis. Infection and Immunity, Washington, v. 64, n. 11, p. 4733-4738, 1996.
YAMAMOTO, Y.; KLEIN, T. W.; FRIEDMAN, H. Involvement of mannose receptor in cytokine interleukin$1 \beta$ (IL-1 $\beta)$, IL-6, and granulocyte-macrophage colonystimulating factor response, but not in chemiokyne macrophage inflammatory protein $1 \beta$ (MIP-1 $\beta$ ), MIP-2, and $\mathrm{KC}$ response, caused by attachment of Candida albicans to macrophage. Infection and Immunity, Washington, v.65, n. 3, p. 1077-1082, 1997. 